Review

\title{
Sustainable Treatment of Aquaculture Effluents-What Can We Learn from the Past for the Future?
}

\author{
Ariel E. Turcios ${ }^{1,2}$ and Jutta Papenbrock ${ }^{1, *}$ \\ 1 Institut für Botanik, Herrenhäuserstr. 2, D-30419 Hannover, Germany; \\ E-Mail: a.turcios@botanik.uni-hannover.de \\ 2 Facultad de Agronomía, Universidad de San Carlos de Guatemala, Guatemala \\ * Author to whom correspondence should be addressed; \\ E-Mail: Jutta.Papenbrock@botanik.uni-hannover.de; \\ Tel.: +49-511-762-3788; Fax: +49-511-762-19262.
}

Received: 23 December 2013; in revised form: 24 January 2014 / Accepted: 8 February 2014 / Published: 20 February 2014

\begin{abstract}
Many aquaculture systems generate high amounts of wastewater containing compounds such as suspended solids, total nitrogen and total phosphorus. Today, aquaculture is imperative because fish demand is increasing. However, the load of waste is directly proportional to the fish production. Therefore, it is necessary to develop more intensive fish culture with efficient systems for wastewater treatment. A number of physical, chemical and biological methods used in conventional wastewater treatment have been applied in aquaculture systems. Constructed wetlands technology is becoming more and more important in recirculating aquaculture systems (RAS) because wetlands have proven to be well-established and a cost-effective method for treating wastewater. This review gives an overview about possibilities to avoid the pollution of water resources; it focuses initially on the use of systems combining aquaculture and plants with a historical review of aquaculture and the treatment of its effluents. It discusses the present state, taking into account the load of pollutants in wastewater such as nitrates and phosphates, and finishes with recommendations to prevent or at least reduce the pollution of water resources in the future.
\end{abstract}

Keywords: aquaculture; aquaponics; halophytes; nutrients; Salicornia spp.; wastewater; wetlands 


\section{Introduction and Aims of the Review}

Worldwide, there is a growing contamination of soil and irrigation water, caused, among other reasons, by intensive agricultural use and environmentally-unfriendly activity, which is due to the need to generate ever greater quantities of food to meet the demands of the growing population.

Today, aquaculture is growing rapidly: according to the FAO [1], aquaculture provides $47 \%$ (51 million tons) of the global human fish consumption. In order to keep up with population growth and increasing per capita fish consumption, aquaculture output is set to increase by a further $60 \%-100 \%$ over the next 20-30 years. In 2015, the production from aquaculture will be 74 million tons [1]. More than $40 \%$ of the world population lives not more than $100 \mathrm{~km}$ away from the coastlines, putting high pressure on the coastal ecosystems. Aquacultures as monocultures have been developed in the last decades, from keeping fish in ponds for easier harvesting to high technological fish farms extensively using feed, hormones and often antibiotics with a known impact on the environment. To achieve sustainability, it is necessary to intensify the production using technologies such as water recirculation systems and proper treatment to optimize this valuable resource. Further, is it important to reduce the pressure on the coastlines and produce large amounts of fish also in inland aquaculture systems close to consumers. In recent years long-forgotten historical approaches have been recovered and adapted to new technologies, such as the parallel production of fish with filter feeders and plants or algae, even in multi-trophic systems [2,3]. This concept is applicable to many standard aquaculture installations, such as ponds or net cages.

With respect to the pollution generated by aquaculture, nitrogen and phosphorus are considered as waste components of fish farming, causing serious environmental problems. In addition, several fish excrete nitrogenous waste products by diffusion and ion exchange through the gills, urine and feces. Decomposition and reuse of these nitrogenous compounds is especially important in aquaculture using recirculation systems due to the toxicity of ammonia and nitrite and the chance of hypertrophication of the environment by nitrate [2].

All aspects of water treatment play a significant role in intensive fish production, because the control and monitoring of water quality is of vital importance to the success or failure of the production. It is therefore necessary to develop new research applications focused on avoiding or at least reducing the negative impacts of aquaculture effluents on the environment. This review aims at giving an overview about aquaculture systems developed in historical times which could still be valuable for the future, about the present problems, and about innovative ideas, especially with respect to the integration of halophytic plants as biofilter in saline aquaculture systems.

\section{Systems Combining Aquaculture and Plants}

Several systems for combining aquaculture and biofiltering plants exist at different levels of more or less sophisticated techniques. The simple co-culture of different fish species from the same trophic level has been practiced for a long time and is known as aquatic polyculture. These organisms share the same biological and chemical processes. The culture systems show only a few synergistic benefits. Some traditional polyculture systems incorporate a greater diversity of species, occupying several niches as extensive cultures within the same pond [4,5]. 
A more advanced system is the integrated multi-trophic aquaculture (IMTA). Here, the by-products or waste from one species are recycled to become inputs as fertilizers or food for another. The term "multi-trophic" refers to the incorporation of species from different trophic or nutritional levels in the same system and this is one potential distinction from polyculture systems [6]. The "integrated" in IMTA refers to the more intensive cultivation of the different species in proximity of each other, connected by nutrient and energy transfer through water. Ideally, the biological and chemical processes in an IMTA system should be balanced. This is achieved through the appropriate selection and ratios of different species providing different ecosystem functions. The co-cultured species are typically more than just biofilters; they are harvestable crops of commercial value. A working IMTA system can result in greater total production based on mutual benefits for the co-cultured species and improved ecosystem health, even if the production of individual species is lower than in monoculture over a short term period $[3,7,8]$.

Recirculating aquaculture systems (RAS) recycle water by running it through filters to remove fish waste and food and then recirculating it back into the tanks. This saves water and the waste gathered can be used in compost or, in some cases, could even be treated and used on land. Aquaponics is a food production system that combines conventional aquaculture practices or RAS, i.e., raising aquatic animals such as snails, fish, crayfish or prawns in tanks, with hydroponics, i.e., cultivating plants in water, in a symbiotic environment $[9,6]$. In conventional aquaculture, excretions from the animals being raised can accumulate in the water and increase toxicity. In an aquaponics system, water from an aquaculture system is fed to a hydroponic system where the by-products are broken down by bacteria into nitrate and ammonium which are utilized by the plants as nutrients. The water is then recirculated back to the aquaculture system. As existing hydroponic and aquaculture farming techniques form the basis for all aquaponics systems, the size, complexity, and types of foods grown in an aquaponics system can vary as much as any system found in either distinct farming discipline $[6,9,10]$.

\section{Historical Overview of Aquaculture and Treatment of Its Effluents}

Aquaculture systems have already been invented by the indigenous inhabitants of Australia. They may have raised eels as early as $6,000 \mathrm{BC}$ by developing about $100 \mathrm{~km}^{2}$ of volcanic floodplains into a complex of channels and dams using woven traps to capture eels and preserve them to eat all year round. The Japanese cultivated seaweed by providing bamboo poles, nets and oyster shells to serve as anchoring surfaces for spores [11]. Aquaponics also has ancient roots, although there is some debate on its first occurrence. First examples of aquaponics systems are found in South China and Thailand where rice was cultivated and farmed in paddy fields in combination with fish. These polycultural farming systems existed in many Far Eastern countries where fish, such as the swamp eel, common and crucian carp, as well as pond snails were raised in the paddies [4]. The Aztecs cultivated agricultural islands in Mexico as early as 1150-1350 BC where plants were raised on stationary (and sometimes movable, "floating gardens") islands in lake shallows, and waste materials dredged from canals and surrounding cities were used to manually irrigate the plants. This method of early agriculture, called chinampa, usually measured roughly $30 \times 2.5 \mathrm{~m}$ or even up to $91 \times 9.1 \mathrm{~m}$ in Tenochtitlan. The agricultural output of the chinampas allowed the postclassic Aztec civilization to flourish. Chinampas were created by staking out the shallow lake bed and then fencing in the rectangle with wattle. The 
fenced-off area was then layered with mud, lake sediment, and decaying vegetation, eventually bringing it above the level of the lake. Often trees such as the willow Salix bonplandiana (H.B.K.)-Kunth, and the cypress Taxodium mucronatum Ten., were planted at the corners to secure the chinampa. Canals navigated by canoe surrounded the islands and were used to raise fish. Waste from the fish fell to the bottom of the canals and was collected to fertilize plants. These stationary or floating gardens had very high crop yields with four (or up to seven) harvests a year [12].

The development of modern aquaponics is often attributed to the various works of the New Alchemy Institute at the North Carolina State University where researchers developed the use of deep water culture hydroponic grow beds in a large-scale aquaponics system in the 70s [6]. Actually, the inorganic compounds in aquaculture systems comply to a large extent with the nutrient requirements of plants and algae. Thus, the potential of process water from RAS for plant cultivation is obvious. Approaches are dated back to 1978 and 1984, when Lewis and co-workers [13] and Watten and Busch [14] combined the production of tilapia and tomatoes. The combination of fish and plant culture where the plants not only act as biofilter but also as food for humans for examples as vegetable, salad, nutraceutical etc. dictates that hormones and chemicals cannot be applied. Also, the sizes of aquaponic systems were optimized and adapted to local use. For example, Canada first saw a rise in aquaponic setups throughout the 90 s, predominantly as large commercial installations raising high-value crops such as trout and lettuce. Findings were made on rapid root growth in aquaponic systems and on closing the solid-waste loop. It was found that owing to certain advantages in the system over traditional aquaculture, the system can run well at a low $\mathrm{pH}$ level, which is favored by plants but not fish. The commercially sized system was adapted to a smaller-scale prototype that can be operated by families, small groups or restaurants [9]. The newest approach in marine aquaculture in the 21 st century is to develop the necessary parameters for the design and construction of an integrated marine recirculation aquaculture system (IMRAS) using different halophyte species [15]. Modern technical filter technologies and long practiced hydroponic systems are combined in a very efficient, hygienic and sustainable way with almost any exchange of water. The reduction of exchanging process water makes the systems ecologically more sustainable and economically more successful.

\section{Present State}

Water is one of the most abundant compounds in nature and covers approximately three quarters of the surface of the earth. Over $97 \%$ of the total water on the planet is in the oceans and other saltwater bodies, and its use is restricted. Of the remaining $3 \%$, above $2 \%$ is in the solid state, which makes it practically inaccessible. Therefore, only the remaining $0.62 \%$ found in lakes, ponds, rivers and groundwater is available for human use such as industrial and agricultural activities. The main problem is its patchy distribution across the planet [16]. The primary renewable source of freshwater is continental rainfall, which generates a global supply of $40,000-45,000 \mathrm{~km}^{3}$ per year. This more or less constant water supply must support the entire world population, which is steadily increasing by roughly 85 million per year [17]. Thus, the availability of freshwater per capita is decreasing rapidly.

The immoderate use of natural resources has a negative effect on the ecosystems from which they are obtained and ecosystems in which they are used. The case of water is one of the best examples; more water consumption by human beings leads to an increase in wastewater discharges. From the 
total of this contaminated water, only a portion is collected in treatment plants, while the rest is discharged to natural systems directly without any pretreatment. It is necessary to establish purification systems before discharging as an important measure for the conservation of the systems [16]. In this context, aquaculture is an activity that requires a high volume of water and therefore a considerable amount of wastewater is discharged. The accumulation of excreta and food waste during fish culture often causes a deterioration of water quality, with negative effects on the fish and on the environment. This wastewater contains considerable amounts of nitrogen, phosphorus and organic matter [18], and can degrade other water bodies. Therefore, an appropriate wastewater treatment process is vital to prevent negative impacts on the surrounding aquatic environment-such as hypertrophication-and for sustaining aquaculture development worldwide.

\subsection{Wastewater Management}

A number of physical, chemical and biological methods used in conventional wastewater treatment have been applied in aquaculture systems. Solids removal is accomplished by sedimentation, sand or mechanical filtration. Biological processes such as submerged biofilters, trickling filters, rotating biological contactors, and fluidized bed reactors are employed for the oxidation of organic matter, nitrification, or denitrification [19]. Rotating microscreens are commonly used in land-based intensive fish-farms in Europe, with a screen mesh pore size of 60-200 $\mu \mathrm{m}$ [18]. These methods do help with phosphorus removal but are costly in terms of capital investment, energy consumption and maintenance requirements; however, little research has been focused on aquaculture wastewater.

Researchers have demonstrated that wetland systems can remove significant amounts of suspended solids, organic matter, nitrogen, phosphorus, trace elements and microorganisms contained in wastewater [20]. The aims of waste treatment and solids management differ, depending on whether the intensive culture system is single-pass flow-through, water reuse with little exchange, or a recirculating water system, as summarized by Losordo and Westers [21]. Removal of solids, organic matter, ammonia and nitrite are critical for the development of recirculating aquaculture systems [22]. In these systems, fish can be cultured next to other organisms, which are converting otherwise discharged nutrients into valuable products [23], and therefore make the system feasible.

\subsubsection{Solids Loads}

In order to maintain the total suspended solids (TSS) at acceptable levels for discharging or recycling, it is important to understand the nature of the waste. Appropriate management practices and/or treatment technology can then be applied as described by Cripps and Bergheim [18]. Many studies and reviews, including Cripps and Kelly [24], have shown that aquaculture waste characteristics are not conducive to easy treatment, because of their low concentrations in the effluent. Fish-farm operations have changed in recent years, due to an intensification of farming. These changes involve an increase in culture density and a decrease in specific water consumption. There have also been improved feeding formulations and systems that reduce losses through runoff. The addition of dietary binders to fish feed, such as Alginate and Guar gum, significantly enhances the stability of fish feces thus favoring the formation of large waste particles with high mechanical removal potential and a considerably improved leaching resistance. These binders have no negative side effects on the health 
of the fish and digestibility of macronutrients [25]. Supporting this, data presented by Kelly et al. [26] and Bergheim et al. [27] showed that treatment efficiency, in terms of the separation of particles from the effluent, increased with increased solids concentration; the settling efficiency of an aquaculture sludge sedimentation chamber increased from about $58 \%$ at about $1 \mathrm{mg}$ suspended solids (SS) $\mathrm{min}^{-1}$ to nearly $90 \%$ at $18 \mathrm{mg} \mathrm{SS} \mathrm{min}^{-1}$ at the same flow rate.

This indicates that aquaculture waste solids are difficult to treat, and that by increasing the concentration prior to treatment, an increase in treatment efficiency, or clarification rate, can be expected [18].

Generally, solid concentrations in the untreated effluent from flow-through farms are around 5-50 $\mathrm{mg} \mathrm{L}^{-1}$, and do not appear to have altered greatly within the last 20 years. This was shown by Hennessy et al. [28], Bergheim et al. [29] and Cripps [30] who reported a wide range of total solid concentrations of 1.6-14.1, 0-20.1, and $6.9 \mathrm{mg} \mathrm{L}^{-1}$, respectively. However, these concentrations can vary widely depending on the management of aquaculture systems.

\subsubsection{Nutrient Load}

The pollution load in wastewater is variable, it depends on several parameters. Kelly et al. [31] found that the waste quantity discharged from a fish farm is directly related to temperature. Foy and Rosell [32] showed that the proportion of nutrients in the particulate fraction increased with temperature. This relationship is based on the fact that an increase in temperature also increases the rate of metabolism. In integrated intensive aquaculture systems, the waste load such as nitrates and phosphates can be reduced if the system fish is cultured with other organisms, such as plants used as biofilter, which can convert nutrient discharges into valuable products. Schneider et al. [23] concluded that the combination of fish culture with subsequent phototrophic and herbivorous conversion increases nutrient retention in the culture system (e.g., $20 \%-42 \%$ feed nitrogen to $29 \%-45 \%$ feed nitrogen). This relative small increase is due to the herbivores, as herbivorous conversion substantially decreases the nutrient retention achieved by phototrophic conversion by $60 \%-85 \%$ feed nitrogen and $50 \%-90 \%$ feed phosphorous.

Other compounds that are present in aquaculture wastewater are feed-derived waste, antibiotics and some hormones, as described by Tacon et al. [33]. The feed-derived waste includes components that are either dissolved, such as phosphorus $(\mathrm{P})$ and nitrogen $(\mathrm{N})$ based nutrients, or that are in the solid phase such as suspended solids, as described by Losordo and Westers [21]. These solids can commonly carry $7 \%-32 \%$ of the total nitrogen (TN) and $30 \%-84 \%$ of the total phosphorus (TP) in wastewater. The remainder is transported out of the farm in the dissolved fraction, because it is largely not possible to remove them by particle separation techniques, which are commonly employed for aquaculture wastewater treatment [18].

Cripps and Kelly [24] found that the amount of SS, TN and TP were commonly low in aquaculture effluents, at about $14,1.4$ and $0.13 \mathrm{mg} \mathrm{L}^{-1}$, respectively. However, this waste may vary depending on the aquaculture system and can cause a negative effect on the environment. Lin et al. [20] reported that nutrient concentrations in a fishpond increased as feed residue and fish excreta accumulated and the influent concentrations in the constructed wetlands system ranged from $0.12-14.7 \mathrm{mg} \mathrm{NH}_{4}-\mathrm{N} \mathrm{L}^{-1}$, $0.02-1.5 \mathrm{mg} \mathrm{NO}_{2}-\mathrm{N} \mathrm{L}^{-1}, 0.01-5.3 \mathrm{mg} \mathrm{NO}_{3}-\mathrm{N} \mathrm{L}^{-1}$, and 3.1-17.7 $\mathrm{mg} \mathrm{PO}_{4}-\mathrm{P} \mathrm{L}^{-1}$. 


\subsubsection{Feed Quality}

Appropriate treatment technology and waste management must be adequate to facilitate the removal of particles as described by Cripps and Bergheim [18]. A very important issue is to improve feed quality, with a greater bio-availability of phosphorus and proteins, reducing the amount of fish excreta. Improved pellet integrity with subsequent slower breakdown rates and optimized feeding systems and protocols has also reduced wastage [18].

The development of "high-energy diets" with increased fat content, reduced carbohydrate levels, reduced protein levels, and improved digestibility has significantly decreased waste production in salmonid farming. In a standard diet for salmonids, the following fractions of the main components were reported by Åsgård and Hillestad [34] to be indigestible and excreted as fecal waste: 13\% of the protein, $8 \%$ of fat, $40 \%$ of carbohydrate (fiber completely indigestible), $17 \%$ of organic matter, $50 \%$ of ashes and $23 \%$ of dry matter; about $40 \%$ of ingested protein $\mathrm{N}$ is excreted as dissolved $\mathrm{N}$ $\left(\mathrm{TAN}=\mathrm{NH}_{3}+\mathrm{NH}_{4}{ }^{+}\right)$by salmon. Recent studies indicate that a minimum of $11 \mathrm{~g} \mathrm{~kg}^{-1}$ dietary $\mathrm{P}$ is required by juvenile Atlantic salmon [35]. The daily nutrition discharges per fish (DND) for nitrogen and phosphorus are predicted by the following equation [36]:

$$
\text { DND }(N, P)=\text { nutrient fed }- \text { nutrient gain }
$$

where

$$
\begin{aligned}
& \text { nutrient fed }=\text { ration fed }(g) X \text { nutrient in feed }\left(g g^{-1} \text { diet }\right) \\
& \text { nutrient gain }=\operatorname{growth}(g) X \text { nutrient in fish }\left(g g^{-1} \text { fish }\right)
\end{aligned}
$$

At a feed conversion ratio (FCR) of $1.0 \mathrm{~kg}$ feed $\mathrm{kg}^{-1}$ gain, the estimated discharges from juvenile salmonids, in terms of $\mathrm{g}(\mathrm{N}, \mathrm{P}) \mathrm{kg}^{-1}$ fish gain, are about $33 \mathrm{~g} \mathrm{~N}$ (26 g dissolved and $7 \mathrm{~g}$ solid-bound) and $7.5 \mathrm{~g} \mathrm{P}(80 \%-90 \%$ solid-bound) [18]. Based on digestibility estimates of typical diets [34], the calculated discharge of suspended solids from salmon and trout farms should be $150-200 \mathrm{~g} \mathrm{SS} \mathrm{kg}^{-1}$ fish gain at a FCR of 0.9-1.0.

As described above, it is clear that the best way to reduce the quantity of discharged waste is to improve the feed management. The required capacity of treatment systems can then be minimized, thus reducing capital and operating costs. Technology for monitoring uneaten pellets has been shown to be a useful means of reducing wastage [37]. Reduced water consumption, often by combining recirculation and addition of oxygen, is a means to improve the utilization of the water supply and to reduce the discharged effluent load because of improved treatment efficiency [38].

\subsubsection{Bead Filters}

Bead filters or expandable granular biofilters (EGBs) can operate as both mechanical and biological filters $[39,40]$ and for this reason they have been used in recycling systems. There are several potential ways for beneficial disposal of organic waste from aquaculture: application on agriculture land, composting, vermiculture and reed drying beds [41,42]. Newly produced sludge from aquaculture is considered a good 'slow-release' fertilizer in agriculture with a high concentration of organic matter, nitrogen and phosphorus, but with a low potassium content $[29,43,44]$. 


\subsubsection{Wetlands}

Constructed wetland technology has grown in popularity for wastewater treatment since the early 1970s [45]. Wetlands are a well-established and cost-effective method for treating wastewater, such as municipal or domestic sewage, industrial and agricultural wastewater, landfill leachate, and stormwater runoff as described by Webb et al. [46] (Figure 1).

Figure 1. Typical man-made constructed wetland for a recirculation system.

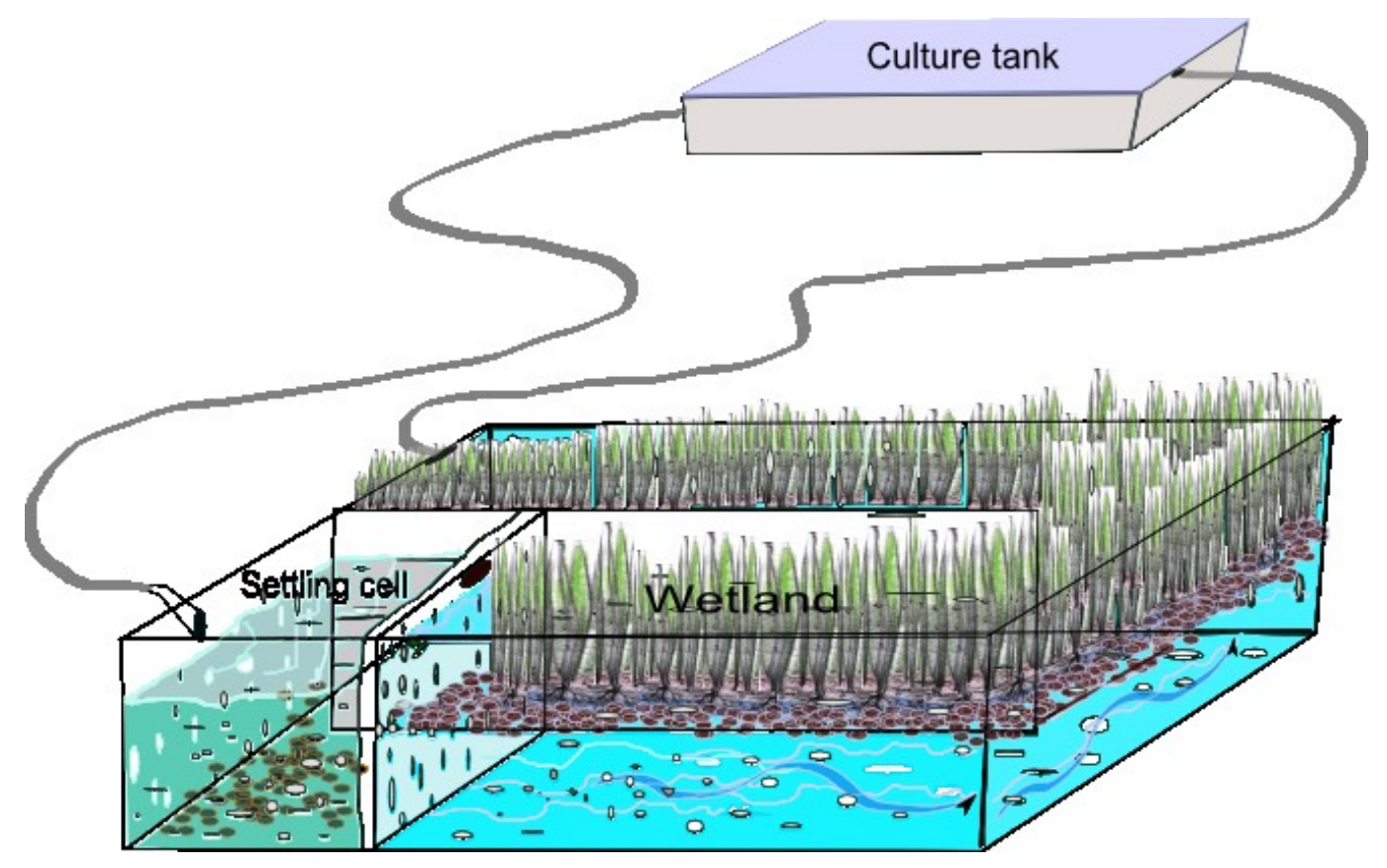

Various biotic and abiotic processes regulate pollutant removal in wetlands [47,48]. Microbial mineralization and transformation (e.g., nitrification-denitrification) and uptake by vegetation are the main biotic processes, whereas abiotic processes include chemical precipitation, sedimentation, and substrate adsorption. Constructed wetlands are characterized by the advantages of moderate capital costs, low energy consumption and maintenance requirements, landscape esthetics and increased wildlife habitat [45].

Sindilariu et al. [49] concluded that compared to standard mechanical effluent treatment the efficiency of the sub-surface flow wetland for TSS polishing is in the range of micro-screening. Webb et al. [46] also demonstrated the effectiveness of wastewater treatment from land-based intensive marine aquaculture farms by constructed wetlands planted with Salicornia spp. Other studies [20,50-52] have demonstrated that constructed wetlands can efficiently remove the major pollutants from catfish, shrimp and milkfish pond effluents, including organic matter, SS, N, P, and phytoplankton under a low hydraulic loading rate (HLR) and long hydraulic retention time (HRT) ranging between $0.018-0.135 \mathrm{~m}^{-1}$ day $^{-1}$ and 1-12.8 days, respectively. These hydraulic conditions would result in a wetland size being $0.7-2.7$ times the size of the pond area for treating the polluted fishpond effluents [20,50]. There are other studies where the size of wetlands varies greatly, as shown by Buhmann and Papenbrock [10]. Based on this, it is important to calculate the right size of the wetland. 


\subsubsection{Wetland Area Estimation}

Pollutant removal in constructed wetlands, as described by Lin et al. [53], can be estimated by using the first-order plug flow kinetic model. This model is given as follows when omitting the background pollutant concentration $[45,47]$ :

$$
\frac{C_{e}}{C_{i}}=\exp (-k t)=\exp \left(-\frac{k \varepsilon h_{w}}{H L R}\right)
$$

Where $C_{\mathrm{i}}=$ influent pollutant concentration $(\mathrm{mg} / \mathrm{L}), C_{\mathrm{e}}=$ effluent pollutant concentration $\left(\mathrm{mg} \mathrm{L}^{-1}\right)$, $t=$ nominal hydraulic retention time (day), $k=$ first-order removal rate constant $\left(\right.$ day $\left.^{-1}\right)$, HLR $=$ hydraulic loading rate $\left(\mathrm{m} \mathrm{day}^{-1}\right), \varepsilon=$ porosity of wetland, and $h_{\mathrm{w}}=$ water depth of wetland $(\mathrm{m})$. The previous equation can be rearranged to provide an estimate of wetlands surface area needed for wastewater treatment:

$$
A_{w}=\frac{Q\left(\ln C_{i}-\ln C_{e}\right)}{k \varepsilon h_{w}}
$$

Where $Q=$ flow rate of wastewater through wetlands $\left(\mathrm{m}^{3} /\right.$ day).

$$
Q=r A_{t} h_{t}
$$

Where $r=$ recirculating ratio is defined as the ratio of daily flow of recirculating water to total water in the culture tank $\left(\right.$ day $\left.^{-1}\right), A_{\mathrm{t}}=$ surface area of the culture tank $\left(\mathrm{m}^{2}\right), h_{\mathrm{t}}=$ water depth of culture tank $(\mathrm{m})$. If Equation (6) is substituted into Equation (5), then the $A_{\mathrm{w}} / A_{\mathrm{t}}$ ratio is found to be given as:

$$
\frac{A_{w}}{A_{t}}=\frac{r h_{1}\left(\ln C_{i}-\ln C_{e}\right)}{K \varepsilon h_{w}}
$$

According to Shpigel et al. [54], using constructed wetland (CW) systems for effluent treatment requires a relatively extensive area. About $10,000 \mathrm{~m}^{2}$ of CW with Salicornia spp. are required to remove nitrogen and total suspended solids produced from $900 \mathrm{~kg}$ of $45 \%$ crude protein fish feed $\left(11 \mathrm{~m}^{2} \mathrm{~kg}^{-1}\right.$ of feed) during one year.

\subsubsection{Salt-Tolerant Plants used as Biofilters in Wetlands}

The expansion of aquaculture and the recent development of more intensive land-based marine farms require commercially-valuable halophytic plants for the treatment of saline wastewater [46]. Research on wastewater treatment has been done using wetlands with halophytic plants (for a classification of plant species tolerant to different salinities see Buhmann and Papenbrock [10]). These plants have a high tolerance to salinity and may be used for absorption of nitrates, phosphates and other compounds. Halophytic plants differ in presence and specificity of aerenchyma which can influence the presence of oxygenated zones within the soil and therefore the growth of certain bacteria and processes such as ammonification and nitrification can take place [10].

Lin et al. [20] used a free water surface flow (FWS) wetland planted with water spinach (Ipomoea aquatic FORSSK.) in the front half and a native weed (Paspalum vaginatum Sw.) in the second half. The subsurface flow (SSF) wetland was planted with common reed (Phragmites australis (CAV.) TRIN. 
EX STEUD.). During initial plant establishment, the wetland water level was kept static, with a water depth of $5 \mathrm{~cm}$ for the FWS and $40 \mathrm{~cm}$ for the SSF. The planting densities were $12 \%$ of wetland cover for the FWS and four plants $\mathrm{m}^{-2}$ for the SSF. The aquatic plants grew rapidly to colonize the wetlands since influent was continuously added. Plants were not harvested during this study [20]. In 2005, Lin et al. [53] reported the use of Cattail (Typha angustifolia L.) and P. australis that were planted in the FWS and SSF cell, respectively. At the beginning, both cells had an initial density of around 6 plants $\mathrm{m}^{-2}$, and at the end of the study, a plant density of more than 90 plants $\mathrm{m}^{-2}$ was observed [53].

The economic attractiveness of a halophytic biofilter can also be upgraded by the use of salt-tolerant species with a commercial value [55]. Brown et al. [2] studied the feasibility of wetlands equipped with different halophytes (Suaeda esteroa Ferren and Whitmore, Salicornia bigelovii Torr. and Atriplex barclayana (Benth.) D. Dietr.) with a potential as forage or oilseed crop as biofilter for saline aquaculture effluents.

Grieve and Suarez [56] found Portulaca oleracea L. to be tolerant for chloride- and sulfate-dominated salinities and to be a valuable, nutritive crop. Plantago coronopus L. has been reported to be a potential cash crop for human consumption. It contains valuable substances such as Vitamins A, C and $\mathrm{K}$ as well as calcium [57]. However, it has been shown that some plants can sequester significant amounts of antibiotics. Therefore, the question of quality control for vegetables has to be solved prior to selling such products.

Buhmann and Papenbrock [10] reported that a series of studies on the purification of recirculating aquaculture process water by constructed mangrove wetlands was conducted, resulting in a faster growth of shrimp in the treatments with water exchange to ponds planted with mangroves (Rhizophora spp.).

\subsubsection{Removal Efficiency of Wetlands}

Lin et al. [20] described that the average removal efficiency of a wetland system was $86 \%-98 \%$ for $\mathrm{NH}_{4}-\mathrm{N},>99 \%$ for $\mathrm{NO}_{2}-\mathrm{N}, 82 \%-99 \%$ for $\mathrm{NO}_{3}-\mathrm{N}$, and $95 \%-98 \%$ for total inorganic nitrogen (TIN). These efficiencies were extremely high and were only slightly affected by the hydraulic loading rate $\left(1.8-13.5 \mathrm{~cm} \mathrm{day}^{-1}\right)$. In the same research, it is stated that the overall removal efficiency for phosphate decreased markedly from $71.2 \%-31.9 \%$ as the hydraulic loading rate increased from $2.3-13.5 \mathrm{~cm}$ day $^{-1}$. This constructed wetland system also performed well with respect to the removal of chemical oxygen demand $(25 \%-55 \%)$, suspended solids $(47 \%-86 \%)$ and chlorophyll a $(76 \%-95 \%)$ from the fishpond effluent. In another research done by Lin et al. [53], the average removal of TSS was $66 \%$ under high hydraulic loading rates (1.57-1.95 m day $\left.{ }^{-1}\right)$. Five-day biochemical oxygen demand $\left(\mathrm{BOD}_{5}\right)$ was, on average, removed by $37 \%$ and $54 \%$ across the FWS-SSF wetland in Phases 1 and 2, respectively. Phase 1 was conducted during a warm season from April to June and Phase 2 was performed during a cold season from August to January. Consequently, overall total ammonia nitrogen (TAN) reduction percentage of the FWS-SSF wetland averaged $66 \%$ and $64 \%$ in Phases 1 and 2, respectively. The whole treatment wetland basically showed effective $\mathrm{NO}_{2}-\mathrm{N}$ removal with average reduction efficiency of $94 \%$ and $83 \%$ (average removal rate of 0.16 and $0.58 \mathrm{~g} \mathrm{~m}^{-2}$ day $^{-1}$ ) in Phases 1 and 2, respectively. In applications for wetland treatment of aquaculture wastewater and recirculating water, an efficient nitrate removal between $68 \%$ and $99 \%$ was demonstrated $[20,58]$. 
The TIN removal efficiency also depends on the nutrient load, which was demonstrated by Webb et al. [46]. Zachritz and Jacquez [59] and Panella et al. [60] concluded that wetlands can also be potentially used for treating the recycling water in a recirculating intensive aquaculture system by operating at higher hydraulic loading rates and consequently with lower removal efficiency. Nevertheless, further research on recirculating aquaculture systems is needed, focusing on higher hydraulic loading rates and their effect on fish growth and environmental effects. With regard to environmental effects, Lin et al. [53] concluded that the treated effluent from wetland cells can be discharged directly to the water body if a partial water exchange or draining after harvesting is necessary. Something important to consider is to keep the $\mathrm{NO}_{3}-\mathrm{N}$ level below $1000-3000 \mathrm{mg} \mathrm{L}^{-1}$ as higher levels are considered toxic to many fish and invertebrates [22].

\subsection{Present Problems}

Wastewater treatments are usually physical processes, including sand and mechanical filters. Biological processes such as submerged biofilters, trickling filters, rotating biological contactors, and fluidized bed reactors are employed in the oxidation of organic matter, nitrification, or denitrification. The disadvantages of these treatment methods are that they produce sludge, require much higher energy and depend on frequent maintenance. The development of an effective, low-cost treatment is therefore imperative if aquaculture is to expand continually at the present rate [59]. Constructed wetland systems are characterized by the advantage of a high effectiveness in the treatment of wastewater, but the disadvantage is that they require a considerable area of land, being 0.7-2.7 times the size of the pond area. Thus, wetland methods may need a large land area when a great amount of aquaculture wastewater needs to be treated. For this reason, there is a concern about the feasibility of wetlands as a cost effective method because wetlands typically require a low hydraulic loading rate and a long hydraulic retention time to achieve efficient pollutant removal [53]. Nevertheless, Sindilariu et al. [61] pointed out that the combination of effective pre-treatment ( $80 \%$ TSS removal) with small constructed wetlands processing high hydraulic loads, are economically most feasible, with annual costs of $€ 15,450$. For a $100 \mathrm{~L} \mathrm{~s}^{-1}$ trout farm with an annual production of $770 \mathrm{~kg}\left(\mathrm{~L} \mathrm{~s}^{-1}\right)^{-1}$, this represents a production cost increase of $€ 0.20 \mathrm{~kg}^{-1}$.

\section{What can be Learned for the Future? Facts and Aspirations}

A large body of good-quality research has been carried out worldwide on different integrated aquaculture systems that use plants to take up waste nutrients and, at the same time, add to the income of the farms. Research over three decades has brought the integrated land-based technology to a commercial reality. Through plant biofilters, often in combination with additional filtering species, integrated aquaculture recycles nutrients into profitable products while restoring water quality. Fish-phytoplankton-shellfish systems convert the fish waste into bivalves, which have a large global market value. Fish-seaweed-macroalgivore (such as abalone and sea urchin) systems have a choice of marketing either the seaweed or the macroalgivore, while they use less land than the fish-phytoplankton-shellfish systems and maintain a more stable water quality. Integrated aquaculture, in both freshwater and seawater, can be profitable, thanks to the sales of the biofilter organisms such as vegetables, shellfish and seaweed. The results are higher yields and income per ton 
of feed and per ton of water. Furthermore, the integrated culture system fulfills, at no extra effort, practically all the requirements of organic aquaculture, a feature that opens up new lucrative markets to the aquaculturist [11].

The development of new finfish species is a high priority for the diversification of the aquaculture in several countries, in order to expand the production to high-value resources and different geographical zones. Cultivation in RAS for the whole life cycle is currently being established. Modern closed RAS can operate with artificial seawater and less than $1 \%$ of water renewal per day. These high-tech systems allow the land-based cultivation of 'exotic' species of high commercial interest, close to the consumer, and with zero discharge of nutrients and organic matter into natural ecosystems when combining with IMTA. Such systems offer the necessary bio-security for the culture of non-native species, water quality control as well as waste management. Biosecure RAS also avoid disease outbreaks and parasites due to the lack of intermediate hosts. Additionally, product traceability is possible. This type of technology is environmentally sound and contributes to the sustainability of aquatic food production [15].

The environmental sustainability of modern RAS does not rely on production results and/or good water parameters only, but also on the optimization of the use of land, energy, feed and water. Recent developments of IMTA systems allow the use of RAS waste products as nutrients, coupling different water loops with the main fish production water system. Another possibility is the implementation of end of pipe treatments such as artificial wetlands. A deeper understanding of the interaction between nutrient inputs (feed), nutrient retention (growth) and outputs (soluble and particulate waste) will help address the sustainability of RAS and integrated land based aquaculture [15].

Good practice in the management of water resources will aim to diminish the cost of water, reducing consumption and maximizing the reuse or recycling of supply water, while returning it to the natural waters with acceptable physicochemical and biological characteristics and, hence, avoiding negative impacts on ecosystems. In this context, there has been a shift towards community integration of aquaponics that offers job opportunities and training while growing food for the community as can be found in several countries (USA, Israel, Germany, The Netherlands) [54]. Taking into consideration that the future development of marine aquaculture will face a paradigm shift, it is important that a modern medium-scale (500 $\mathrm{mt}^{-1}$ ) urban RAS is able to deliver high quality fish and other aquaculture products to niche markets in areas with high population density [15]. In addition, aquaponic gardeners from all around the world have gathered on online community sites and forums to share their experiences and promote the development of this form of gardening. Recently, aquaponics has been moving towards indoor production systems. Entrepreneurs are utilizing vertical designs to grow food all year round [62].

\section{The Potential Use of Salicornia spp. in Aquaponics}

The limited resources of fresh water for agriculture, aquaculture and the ongoing increase in soil salinity throughout the world demands the development of new crops that are able to tolerate higher salt concentrations than conventional agricultural crops [63,64]. Different species of Salicornia have been studied recently, demonstrating their high potential as new salt-tolerant crop plants based on their tolerance to high salt concentrations up to seawater concentration, and potential use for food, fodder, 
acting as biofilter for treating wastewater, oil production, gas production and other industrial uses (Figure 2).

It was experimentally shown that Salicornia spp. has a great potential for extracting inorganic contaminants from wastewater, such as nitrates and phosphates. As Buhmann and Papenbrock [10] pointed out, there are currently various approaches to tap the market for halophytes especially for Salicornia spp. as vegetable as well as using halophytes as biofilter and valuable side product for aquaculture wastewater treatment in temperate and subtropical regions.

In the same review, Buhmann and Papenbrock [10] stated that the halophytic plants recycle the nutrients generated in a fish culture in terms of biomass production and contribute to maintain appropriate quality in the process water of the recirculating aquaculture system. One of the main problems using plants as biofilters is that after their useful life, their high salt-containing biomass is discarded and can contaminate other resources. To permanently remove the nutrients taken up by plants and to no longer return them to the water bodies, it is important to harvest them frequently and use the biomass for food and fodder and think about meaningful applications for the rest of the plants. The income generated from selling Salicornia spp. as an agricultural crop, together with savings on water treatment and potential fines, contributes to the system's economical viability as described by Shpigel et al. [54]. Especially, the cultivation of Salicornia spp. in aquaponic systems shows many advantages over sand or soil cultures, such as controllability, reproducible mass cultures of high numbers, hygienic aspects etc. (Figure 2).

As Salicornia spp. is a new fresh vegetable for human consumption, product quality is a major concern. Salicornia spp. shoots are not only a good source of minerals, but they also contain proteins, various vitamins [65] and higher total lipid and omega-3 contents than spinach, lettuce and mustard green leaves [66]. Thus, Salicornia ecotypes may attract considerable interest as an alternative source of polyunsaturated fatty acids for human consumption, even when grown on full-strength seawater [67].

Figure 2. One of the promising Salicornia species in hydroponic culture is Salicornia dolychostachya Moss. Photos: Christian Boestfleisch, Institute of Botany, Hannover.

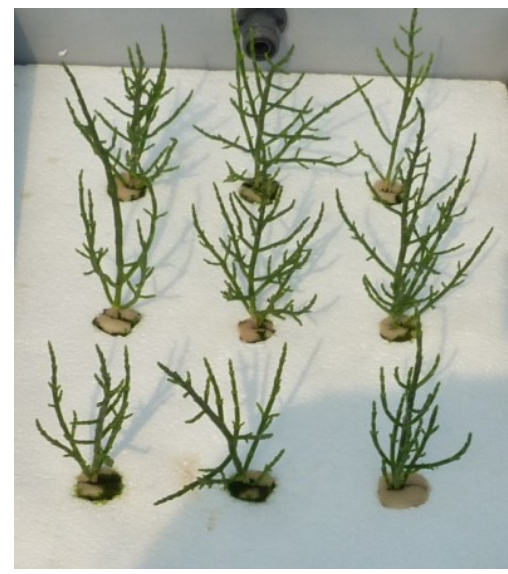

week 1

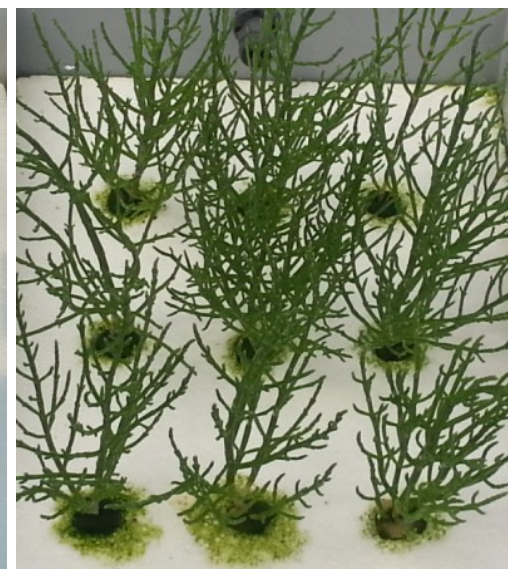

week 4

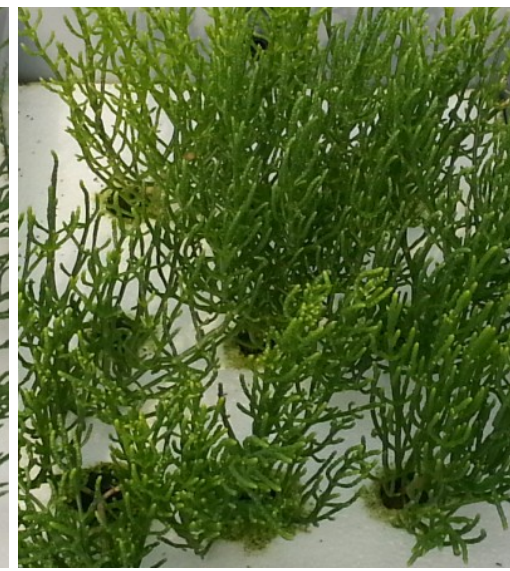

week 6 
As a new crop plant, several growing conditions and selection of genotypes need to be optimized before commercial success is guaranteed [67,68]. With respect to growing conditions, the nutritional content of Salicornia can vary depending on salinity. Yousif et al. [69] reported a decline in the content of $\mathrm{K}^{+}, \mathrm{Ca}^{2+}$ and $\mathrm{Mg}^{2+}$ cations with increasing $\mathrm{Na}^{+}$availability which has been noted for both halophytes and non-halophytic plants, while augmented $\mathrm{Cl}^{-}$contents are believed to have antagonistic effects on $\mathrm{NO}_{3}{ }^{-}$uptake. Nevertheless, Ventura et al. [67] reported no changes in these elements with high salt concentrations, with the following effects on ion concentrations in the shoots: no change in $\mathrm{Ca}^{2+}$ and $\mathrm{Mg}^{2+}$, a slight increase in $\mathrm{K}^{+}$, and marked elevations in $\mathrm{Na}^{+}$and $\mathrm{Cl}^{-}$. Total polyphenol, $\beta$-carotene and ureides, all known for their antioxidant capacities, rose with increasing seawater percentage, which indicated improved nutritional values for Salicornia spp. irrigated with high concentrations of seawater. These plants have high total shoot lipid contents of up to $2.41 \mathrm{mg} \mathrm{g}^{-1}$ fresh weight, which includes an omega-3 fraction of $47.6 \%$ of the total fatty acid content. Therefore, the high fatty acid content of the annual Salicornia spp. was not significantly affected by increasing salt concentrations [67].

Biogas production can be another important use of the Salicornia spp. biomass. The preservation of the environment and the increasing consumption of energy resources are two important aspects, requiring the application of new low-cost technologies for the reuse of waste, conducive to obtaining other useful products such as biogas. Today, the search for renewable energy sources is a challenge for humanity. Worldwide, the use of renewable energy sources is indispensable for development which ensures not only the production of fuel, but in many cases, eliminating waste pollutants that harm the environment. From this point of view, even high salt-containing Salicornia spp. biomass can be used for biogas production, through an anaerobic process after optimization. To date, there are no data and experiences on this topic, which is one of the research activities carried out at the Institute of Botany, Leibniz University Hannover, Germany.

\section{The Potential Use of Mangroves}

For tropical regions, the use of plants as biofilter is also promising. Actually, many aquacultural ponds have been constructed in previous mangrove areas. After the recent strong Tsunami events, it has been more and more realized how important mangroves are for the protection and stability of the coastlines. Mangroves also promote biodiversity because their roots provide shelter for fish, mammals and invertebrates and they have a high economic and ecological value because they act as fishponds. Fish growth is conducted under their roots, so these plants are fundamental to ensure the sustainability of the fishing industry (Figure 3). At the same time, mangroves contribute to nutrient retention, protection and stabilization of shorelines, preserving water quality, climatic regulation and erosion prevention. Mangroves are being widely used to treat wastewater and simultaneously can give protection against natural disasters. Coastal wetlands, such as reefs, marshes and mangroves, act as first-line defenses against the potential devastation through tsunamis and storm events. Mangrove forests occupy 14,650,000 ha of coastline globally [70], with an economic value on the order of 200,000-900,000 USD ha ${ }^{-1}$ [71]. Regardless of their monetary value, mangrove ecosystems are important habitats, especially in developing countries, and play a key role in human sustainability and livelihoods [72], being heavily used traditionally for food, timber, fuel, and medicine [73]. 
Figure 3. Mangrove forest in Tamil Nadu, India. Mangrove roots provide a tangled underwater habitat for many marine species. Photo: Jutta Papenbrock, Institute of Botany, Hannover.

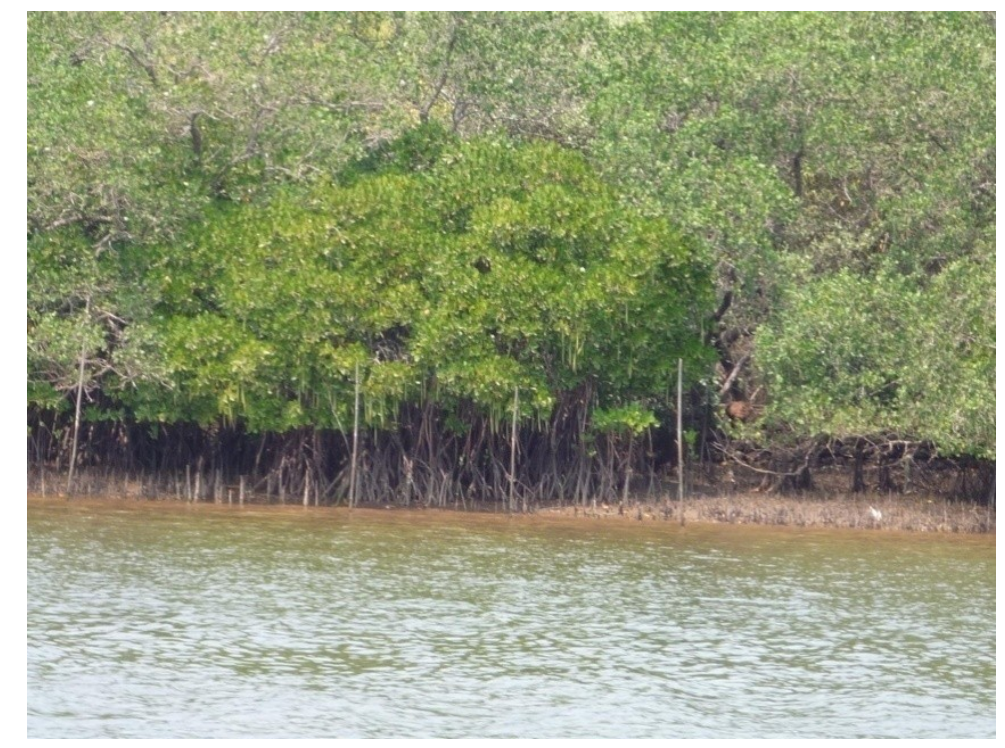

Mangrove forests can attenuate wave energy, preventing the damage caused by tsunamis, as shown by various modeling and mathematical studies [74-79] which indicate that the magnitude of absorbed energy strongly depends on forest density, diameter of stems and roots, forest floor slope, bathymetry, the spectral characteristics (height, period, etc.) of the incident waves, and the tidal stage at which the wave enters the forest. For instance, one model estimates that at high tide in a Rhizophora-dominated forest, there is a $50 \%$ decline in wave energy by $150 \mathrm{~m}$ into the forest [74]. Moreover, Mazda et al. [77] highlighted that the thickly grown mangrove leaves effectively dissipate high wave energy which occurs during storms such as typhoons and, therefore, protect coastal areas.

Especially in rural tropical areas, aquacultures provide a source of income and employment opportunities and therefore aid economic and social development. A very attractive idea is to combine all positive effects of mangroves to make aquaculture in the tropics more environmentally friendly. Vegetation could be used to filter waste water from aquaculture and additionally provide biodiversity, coastal protection and economic services to the community. First trials have been successfully conducted, for example in the Philippines [80]. However, more research is necessary and the idea needs to be promoted in a more professional way in several tropical countries.

\section{Outlook}

In order to feed the growing population in the world with well-balanced food of sufficient quality, the development of sustainable aquacultural systems is fundamental. Several ways to improve the systems currently used are described and discussed in this review. Optimized RAS combined with biofiltering organisms such as plants or algae seem to be the most promising way. Actually, due to their highly flexible metabolism, higher plants might be even more suitable to act as biofilters than algae. Plants have evolved sophisticated detoxification systems against several xenobiotics following the uptake. Different plant species might be able to degrade and/or detoxify hormones and antibiotics sometimes used in aquaculture. The plants might reduce toxicity and sequester the xenobiotics in 
phytotransformation. This could also be a very important aspect in using plants as biofiltering organisms for the future.

\section{Acknowledgements}

Financial support of Ariel Turcios by the DAAD and the Universidad de San Carlos de Guatemala is gratefully acknowledged. We would like to thank Maike Paul, Hannover, for correcting the English language. We acknowledge the support by Deutsche Forschungsgemeinschaft and Open Access Publishing Fund of Leibniz Universität Hannover.

\section{Author Contributions}

The basic structure of this paper was suggested by Jutta Papenbrock. In all other aspects both authors contributed equally to this article.

\section{Conflicts of Interest}

The authors declare no conflict of interest.

\section{References}

1. FAO. The State of World Fisheries and Aquaculture; Food and Agriculture Organization of the United Nations: Rome, Italy, 2012.

2. Brown, J.J.; Glenn, E.P.; Fitzsimmons, K.M.; Smith, S.E. Halophytes for the treatment of saline aquaculture effluent. Aquaculture 1999, 175, 255-268.

3. Neori, A.; Shpigel, M. Algae treat effluents and feed invertebrates in sustainable integrated mariculture. World Aquaculture 1999, 30, 46-49.

4. Binh, C.T.; Phillips, M.J.; Demaine, H. Integrated shrimp-mangrove farming systems in the Mekong Delta of Vietnam. Aquaculture Res. 1997 28, 599-610.

5. Fernando, C. Bitter harvest-rice fields and fish culture. World Aquaculture 2002, 33, $23-24$.

6. Marton, E. Polycultures of fishes in aquaponics and recirculating aquaculture. Aquaponics $J$. 2008, 48, 28-33.

7. Neori, A.; Ragg, N.L.C.; Shpigel, M. The integrated culture of seaweed, abalone, fish and clams in modular intensive land-based systems: II. Performance and nitrogen partitioning within an abalone (Haliotis tuberculata) and macroalgae culture system. Aquacult. Eng. 1998, 15, 215-239.

8. Naylor, R.L.; Goldburg, R.J.; Primavera, J.H.; Kautsky, N.; Beveridge, M.C.M.; Clay, J.; Folke, C.; Lubchenco, J.; Mooney, H.; Troell, M. Effect of aquaculture on world fish supplies. Nature 2000 405, 1017-1024.

9. Rakocy, J.E.; Masser, M.P.; Losordo, T.M. Recirculating aquaculture tank production systems: Aquaponics-Integrating fish and plant culture. SRAC Publication 2006, 454, 16.

10. Buhmann, A.; Papenbrock, J. Biofiltering of aquaculture effluents by halophytic plants: Basic principles, current uses and future perspectives. Environ. Exp. Bot. 2013, 92, 122-133. 
11. Neori, A.; Chopin, T.; Troell, M.; Buschmann, A.H.; Kraemer, G.P.; Halling, C.; Shpigel, M.; Yarish, C. Integrated aquaculture: rationale, evolution and state of the art emphasizing seaweed biofiltration in modern mariculture. Aquaculture 2004, 231, 361-391.

12. Van Tuerenhout, D.R. The Aztecs: New Perspectives; ABC-CLIO: Santa Barbara, CA, USA, 2005 ; p. 106.

13. Lewis, W.M.; Yopp, J.H.; Schramm, H.L.; Brandenburg, A.M. Use of hydroponics to maintain quality of recirculated water in a fish culture system. T. Am. Fish. Soc. 1978, 107, 92-99.

14. Watten, B.J.; Busch, R.L. Tropical production of tilapia (Sarotherodon aurea) and tomatoes (Lycopersicon esculentum) in a small-scale recirculating water system. Aquaculture 1984, 41, 271-283.

15. Orellana, J.; Waller, U.; Wecker, B. Culture of yellowtail kingfish (Seriola lalandi) in a marine recirculatingaquaculture system (RAS) with artificial seawater. Aquacult. Eng. 2013, 10.1016/j.aquaeng.2013.09.004.

16. Turcios, A.E. Evaluación de la calidad de las aguas residuales provenientes de la planta de tratamiento Aurora II con fines de riego en el cultivo de frijol (Phaseolus vulgaris L.). Master Thesis, Universidad de San Carlos de Guatemala, Guatemala, June 2011.

17. Stikker, A. Water today and tomorrow. Futures 1998, 30, 43-62.

18. Cripps, S.J.; Bergheim, A. Solids management and removal for intensive land-based aquaculture production systems. Aquacult. Eng. 2000, 22, 33-56.

19. Van Rijn, J. The potential for integrated biological treatment system in recirculating fish culture. Aquaculture 1996, 139, 181-201.

20. Lin, Y.F.; Jing, S.R.; Lee, D.Y.; Wang, T.W. Nutrient removal from aquaculture wastewater using a constructed wetlands system. Aquaculture 2002, 209, 169-184.

21. Losordo, T.M.; Westers, H. System carrying capacity and flow estimation. In Aquaculture Water Reuse Systems: Engineering Design and Management; Timmons, M.B., Losordo, T.M., Eds.; Elsevier: Amsterdam, The Netherlands, 1994; pp. 9-60.

22. Lawson, T.B. Fundamentals of Aquaculture Engineering; Chapman \& Hall: New York, NY, USA, 1995.

23. Schneider, O.; Sereti, V.; Eding, E.H.; Verreth, J.A.J. Analysis of nutrient flows in integrated intensive aquaculture systems. Aquacult. Eng. 2005, 32, 379-401.

24. Cripps, S.J.; Kelly, L.A. Reductions in wastes from aquaculture. In Aquaculture and Water Resource Management; Baird, D.J., Beveridge, M.C.M., Kelly, L.A., Muir, J.F., Eds.; Blackwell: Oxford, UK, 1996; pp. 166-201.

25. Brinker, A.; Koppe, W.; Rösch, R. Optimised effluent treatment by stabilised trout faeces. Aquaculture 2005, 249, 125-144.

26. Kelly, L.A.; Bergheim, A.; Stellwagen, J. Particle size distribution of wastes from freshwater fish farms. Int. J. Aquaculture 1997, 5, 65-78.

27. Bergheim, A.; Cripps, S.J.; Liltved, H.A. System for the treatment of sludge from land-based fish-farms. Aquat. Living Resour. 1998, 11, 279-287.

28. Hennessy, M.; Wilson, L.; Struthers, W. Management Strategies for Salmon Farm Effluents; Scottish Salmon Growers' Association: Perth, UK, 1991. 
29. Bergheim, A.; Kristiansen, R.; Kelly, L.A. Treatment and Utilization of Sludge from Landbased Farms for Salmon. In Techniques for Modern Aquaculture, Proceedings of an Aquaculture Engineering Conference, Spokane, WA, USA, 21-23 June 1993; Wang, J.-W., Ed.; American Society of Agriculture Engineers: St. Joseph, MI, USA, 1993; pp. 486-495.

30. Cripps, S.J. Serial particle size fractionation and characterisation of an aquacultural effluent. Aquaculture 1995, 133, 323-339.

31. Kelly, L.A.; Bergheim, A.; Hennessy, M.M. Predicting output of ammonium from fish farms. Water Res. 1994, 28, 1403-1405.

32. Foy, R.H.; Rosell, R. Loadings of nitrogen and phosphorus from a Northern Ireland fish farm. Aquaculture 1991, 96, 17-30.

33. Tacon, A.G.J.; Phillips, M.J.; Barg, U.C. Aquaculture feeds and the environment: The Asian experience. Water Sci. Tech. 1995, 31, 41-59.

34. Åsgård, T.; Hillestad, M. Technological and Nutritional Aspects of Safe Food Production. EcoFriendly Aquafeed and Feeding. In Proceedings of the Symposium Victam 98, Utrecht, The Netherlands, 13-14 May 1998; p. 16.

35. Åsgård, T.; Shearer, K.D. Dietary phosphorus requirement of juvenile Atlantic salmon Salmo salar L. Aquaculture Nutr. 1997, 3, 17-23.

36. Einen, O.; Holmefjord, I.; Åsgård, T.; Talbot, C. Auditing nutrient discharges from fish farms: Theoretical and practical considerations. Aquacult. Res. 1995, 26, 701-713.

37. Summerfelt, S.T.; Holland, K.H.; Hankins, J.A.; Durant, M.D. A hydroacoustic waste feed controller for tank systems. Water Sci. Tech. 1995, 31, 123-129.

38. Cripps, S.J.; Bergheim, A. Multi-Stage Waste Reduction Technology for Land-Based Aquaculture. In Technical Solutions in the Management of Environmental Effects of Aquaculture, Proceedings of The Scandinavian Association of Agricultural Scientists, Seminar No. 258; Helsinki, Finland, 13-15 September 1995; pp. 50-61.

39. Chen, S.; Coffin, D.E.; Malone, R.F. Production, Characteristics, and Modeling of Aquacultural Sludge from a Recirculating Aquacultural System Using a Granular Media Biofilter. In Techniques for Modern Aquaculture, Proceedings of an Aquacultural Engineering Conference, Spokane, WA, USA, 21-23 June 1993; Wang, J., Ed.; American Society of Agricultural Engineers: St Joseph, MI, USA, 1993; pp. 16-25.

40. Chen, S.; Timmons, M.B.; Aneshansley, D.J.; Bisogni, J.J. Suspended solids characteristics from recirculating aquacultural systems and design implications. Aquaculture 1993, 112, 143-155.

41. Tchobanoglous, G.; Burton, F.L. Wastewater Engineering: Treatment, Disposal and Reuse, 3rd ed.; McGraw-Hill: New York, NY, USA, 1991; p. 1334.

42. Summerfelt, S.T. Waste-handling systems. In Aquacultural Engineering Handbook; Bartali, E., Wheaton, F., Eds.; American Society of Agricultural Engineers: St Joseph, MI, USA,1999; pp. 309-350.

43. Bergheim, A.; Sanni, S.; Indrevik, G.; Hølland, P. Sludge removal from salmonid tank effluent using rotating microsieves. Aquacult. Eng. 1993, 12, 97-109.

44. Westerman, P.W.; Hinshaw, J.M.; Barker, J.C. Trout manure characterization and nitrogen mineralization rate. In Techniques for Modern Aquaculture, Proceedings of an Aquaculture 
Engineering Conference, Spokane, WA, USA, 21-23 June 1993; Wang, J.-W., Ed.; American Society of Agriculture Engineers: St. Joseph, MI, USA, 1993; pp. 35-43.

45. International Water Association. Constructed Wetlands for Pollution Control. Processes, Performance, Design and Operation; IWA Publishing: London, UK, 2000; p. 156.

46. Webb, J.M.; Quinta, R.; Papadimitriou, S.; Norman, L.; Rigby, M.; Thomas, D.N.; Le Vay, L. Halophyte filter beds for treatment of saline wastewater from aquaculture. Water Res. 2012, 46, 5102-5114.

47. Kadlec, R.H.; Knight, R.L. Treatment Wetlands; CRC Press: Boca Raton, FL, USA, 1996.

48. United States Environmental Protection Agency. Manual for Constructed Wetlands Treatment of Municipal Wastewaters; 2000, 1-165, Cincinnati, 2000; EPA/625/R-99/010. Available online: http://www.epa.gov/ORD/NRMRL (accessed on 16 December 2013).

49. Sindilariu, P.D.; Schulz, C.; Reiter, R. Treatment of flow-through trout aquaculture effluents in a constructed wetland. Aquaculture 2007, 270, 92-104.

50. Schwartz, M.F.; Boyd, C.E. Constructed wetlands for treatment of channel catfish pond effluents. Prog. Fish-Cult. 1995, 57, 255-267.

51. Sansanayuth, P.; Phadungchep, A.; Ngammontha, S.; Ngdngam, S.; Sugasem, P.; Hoshino, H.; Ttabucannon, M.S. Shrimp pond effluent: Pollution problems and treatment by constructed wetlands. Water Sci. Tech. 1996, 34, 93-98.

52. Lin, Y.F.; Jing, S.R.; Lee, D.Y.; Wang, T.W. Removal of solids and oxygen demand from aquaculture wastewater with a constructed wetland system in the start-up phase. Water Environ. Res. 2002, 74, 136-141.

53. Lin, Y.F.; Jing, S.R.; Lee, D.Y.; Chang, Y.; Chen, Y. Performance of a constructed wetland treating intensive shrimp aquaculture wastewater under high hydraulic loading rate. Environ. Pollut. 2005, 134, 411-421.

54. Shpigel, M.; Ben-Erza, D.; Shauli, L.; Sagi, M.; Ventura, Y.; Samocha, T.; Lee, J.J. Constructed wetland with Salicornia as a biofilter for mariculture effluents. Aquaculture 2013, 412-413, 52-63.

55. Buhmann, A.; Papenbrock, J. An economic point of view, secondary compounds in halophytes. Funct. Plant Biol. 2013, 40, 952-967.

56. Grieve, C.M.; Suarez, D.L. Purslane (Portulaca oleracea L.): A halophytic crop for drainage water reuse systems. Plant Soil 1997, 192, 277-283.

57. Koyro, H.-W. Effect of salinity on growth, photosynthesis, water relations and solute composition of the potential cash crop halophyte Plantago coronopus L. Environ. Exp. Bot. 2006, 56, 136-146.

58. Lin, Y.F.; Jing, S.R.; Lee, D.Y. The potential use of constructed wetlands in a recirculating aquaculture system for shrimp culture. Environ. Pollut. 2003, 123, 107-113.

59. Zachritz, W.H.; Jacquez, R.B. Treating intensive aquaculture recycled water with a constructed wetlands filter system. Constructed Wetlands for Water Quality Improvement; Moshiri, G.A., Ed.; Lewis Publishers: Boca Raton, FL, USA, 1993; pp. 609-613.

60. Panella, S.; Cignini, I.; Battilotti, M.; Falcucci, M.; Hull, V.; Milone, N.; Monfrinotti, M.; Mulas, G.A.; Pipornetti, G.; Tancioni, L.; et al. Ecodepuration performances of a small-scale experimental constructed wetland system treating and recycling intensive aquaculture wastewater. Ann. Ny. Acad. Sci. 1999, 879, 427-431. 
61. Sindilariu, P.D.; Brinker, A.; Reiter, R. Factors influencing the efficiency of constructed wetlands used for the treatment of intensive trout farm effluent. Ecol. Eng. 2009, 35, 711-722.

62. Chicago Tribune. Available online: http://articles.chicagotribune.com (accessed on 29 January 2014).

63. Simopoulos, A.P. Omega-3 fatty acids and antioxidants in edible wild plants. Biol. Res. 2004, 37, 263-277.

64. Yensen, N.P. Halophyte uses for the twenty-first century. In Ecophysiology of High Salinity Tolerant Plants; Khan, M.A., Weber, D.J., Eds.; Springer Verlag: Heidelberg, Germany, 2006; pp. 367-397.

65. Glenn, E.P.; Brown, J.J.; Blumwald, E. Salt tolerance and crop potential of halophytes. Crit. Rev. Plant. Sci. 1999, 18, 227-255.

66. Lu, Z.; Hodges, R.M.; Mota-Urbina, C.J.; Gallawa, P.L.; Chaturvedi, R.; DeCianne, D.M.; Glenn, E.P.; Hodges, C.N. Salicornia bigelovii (Chenopodiaceae) - a seawater irrigated crop with versatile commercial products. In Proceedings of the 5th New Crops Symposium, Atlanta, Georgia, 10-13 November 2001.

67. Ventura, Y.; Wuddineh, W.; Myrzabayeva, M.; Alikulov, Z.; Khozin, I.; Shpigel, M.; Samocha, T.; Sagi, M. Effect of seawater concentration on the productivity and nutritional value of annual Salicornia and perennial Sarcocornia halophytes as leafy vegetable crops. Sci Hortic. 2011, 128, 189-196.

68. Singh, D. Salicornia as a Multi-Purpose Plant: Acting As A Biofilter, Serving As Vegetable And Producing Valuable Secondary Compounds. Master Thesis, Leibniz University Hannover, Germany, September 2013.

69. Yousif, B.S.; Nguyen, N.T.; Fukuda, Y.; Hakata, H.; Okamoto, Y.; Masaoka, Y.; Saneoka, H. Effect of salinity on growth, mineral composition, photosynthesis and water relations of two vegetable crops; New Zealand spinach (Tetragonia tetragonioides) and water spinach (Ipomoea aquatica). Int. J. Agr. Biol. 2010, 12, 211-216.

70. Wilkie, M.L.; Fortuna, S. Status and trends in mangrove area extent worldwide; Forest Resources Assessment Working Paper 63; Forest Resources Division, FAO: Rome, Italy, 2003. Available online: http://www.fao.org/docrep/007/j1533e/J1533E00.htm (accessed on 16 December 2013).

71. UNEP-WCMC. In the Front Line: Shoreline Protection and Other Ecosystem Services from Mangroves and Coral Reefs; UNEP-WCMC: Cambridge, UK, 2006; p. 33.

72. Alongi, D.M. Present state and future of the world's mangrove forests. Environ. Conservat. 2002, 29, 331-349.

73. Saenger, P. Mangrove Ecology, Silviculture and Conservation; Kluwer Academic: Dordrecht, The Netherlands, 2002.

74. Brinkman, R.M.; Massel, S.R.; Ridd, P.V.; Furukawa, K. Surface Wave Attenuation in Mangrove Forests. In Proceedings of 13th Australasian Coastal and Ocean Engineering Conference, University of Canterbury, New Zealand, 7-11 September 1997; Pacific Coasts and Ports 1997, pp. 941-949.

75. Mazda, Y.; Wolanski, E.; King, B.; Sase, A.; Ohtsuka, D.; Magi, M. Drag force due to vegetation in mangrove swamps. Mangroves Salt Marshes 1997, 1, 193-199.

76. Massel, S.R.; Furukawa, K.; Brinkman, R.M. Surface wave propagation in mangrove forests. Fluid Dynam. Res. 1999, 24, 219-249. 
77. Mazda, Y.; Magi, M.; Ikeda, Y.; Kurokawa, T.; Asano, T. Wave reduction in a mangrove forest dominated by Sonneratia sp. Wetl. Ecol. Manag. 2006, 14, 365-378.

78. Quartel, S.; Kroon, A.; Augustinus, P.G.E.F.; van Santen, P.; Tri, N.H. Wave attenuation in coastal mangroves in the Red River Delta, Vietnam. J. Asian Earth Sci. 2007, 29, 576-584.

79. Alongi, D.M. Mangrove forests: Resilience, protection from tsunamis, and responses to global climate change. Estuar. Coast. Shelf. Sci. 2008, 76, 1-13.

80. Primavera, J.H.; Altamirano, J.P.; Lebata, M.; Reyes, A.A.; Pitogo, C.L. Mangroves and shrimp pond culture effluents in Aklan, Panay Is., Central Phillipines. B. Mar. Sci. 2007, 80, 795-804.

(C) 2014 by the authors; licensee MDPI, Basel, Switzerland. This article is an open access article distributed under the terms and conditions of the Creative Commons Attribution license (http://creativecommons.org/licenses/by/3.0/). 